\title{
Freshness evaluation of fish by quality index method (QIM) and instrumental method at Veraval Fish Landing Centre
}

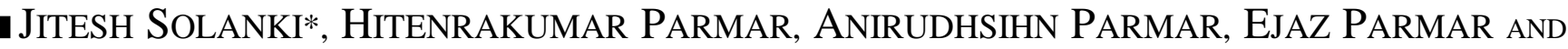 \\ MiLAN MASANI \\ Department of Harvest and Post Harvest Technology, College of Fisheries Science (J.A.U.), VERAVAL (GUJARAT) INDIA
}

*Author for Correspondence

Research chronicle : Received : 22.12.2015; Revised : 13.04.2016; Accepted : 27.04.2016

SUMMARY :

Fisheries has always been the main industries in the Veraval (Gujarat) and are dominated by the Fisherman. Veraval is home to a large number of fish processing factories in G.I.D.C. which export prime quality seafood to USA, Japan, SE Asian, Gulf and EU Countries. For that it required a very fresh quality raw material. Freshness makes a major contribution to the quality of fish or fishery products. For all kinds of products, freshness is essential for the quality of the final product. In this study freshness evaluation of selected fish species from single and multi-day fishing carried out at Veraval fish landing centre. Quality Index Method (QIM) and Distell Fish Freshness Meter (Model Torrymeter) are the most accurate and widely used methods to evaluate the fish freshness. The parameter for the basic of these are skin, smell, eyes, gills, colour and general appearance.

KEY WORDS : Fish, Quality indexed method, Instrumental method freshness, Meter score sheet

How to cite this paper : Solanki, Jitesh, Parmar, Hitendrakumar, Parmar, Anirudhsihn, Parmar, Ejaz and Masani, Milan (2016). Freshness evaluation of fish by quality index method (QIM) and instrumental method at Veraval Fish Landing Centre. Internat. J. Proc. \& Post Harvest Technol., 7 (1) : 42-46. DOI: 10.15740/HAS/ IJPPHT/7.1/42-46 